\title{
EFFECTS OF WATER DEFICIT ON THE GROWTH AND CHLOROPHYLL CONTENT OF Capsicum Frutescens
}

\author{
NORHAYATI YUSUF* AND NUR FAIRUZ IZWANI HAMED \\ Faculty of Science and Marine Environment, Universiti Malaysia Terengganu, 21030 Kuala Nerus, Malaysia.
}

*Corresponding author: yatiyusuf@umt.edu.my

Submitted final draft: 21 September $2020 \quad$ Accepted: 18 November $2020 \quad$ http://doi.org/10.46754/jssm.2021.08.013

\begin{abstract}
Water stress can have major impacts on plant growth through the unbalanced formation of reactive oxygen species (ROS). High production of ROS during water stress can reduce crop yield, thus affecting productivity. Thus, this study determines the effect of water deficit on growth and chlorophyll content of Capsicum frutescens. The Capsicum frutescens were treated with $0,20,40,60,80$ and $100 \mathrm{~mL}$ of water for 20 days. The growth and chlorophyll content were measured at $0,5,10,15$, and 20 days of treatment periods. Water stress did not significantly affect the plant height and stem diameter of the $C$. frutescens subjected to different volumes of water. The total number of leaves, leaf area, as well as fresh and dry weights were unaffected at early stages. However, all parameters increased significantly at the end of the treatment, especially in plants treated with 80 and $100 \mathrm{~mL}$ of water. The chlorophyll content was unchanged at earlier stages of the experiment. However, the chlorophyll content reduced drastically at later stages of the experiment period. The results reveal that different volumes of water did not significantly affect the growth of $C$. frutescens. In contrast, the chlorophyll content of $C$. frutescens was significantly decreased by water stress.
\end{abstract}

Keywords: Water stress, reactive oxygen species, Capsicum frutescens, growth, chlorophyll content.

\section{Introduction}

Reactive oxygen species (ROS) are considered as by-products of plant aerobic metabolism and are generated in several cellular compartments, especially the chloroplast, mitochondria and peroxisomes (Dietz et al., 2016). Under normal conditions, ROS are present in small amounts and well-ordered levels. However, under unfavourable biotic and abiotic circumstances, plants generate huge numbers of ROS, resulting in profound or irreversible effects on the cellular redox state, which can eventually lead to oxidative stress (Nita \& Grzybowski, 2016). Oxidative stress is a common phenomenon in organisms exposed to water stress, as well as many other abiotic stresses, thus adversely limiting the development of tissues and organs, often leading to abnormal plant growth, subsequently affecting the productivity of crop plants. It is a universal problem, restricting the global crop production seriously, and recent global climate change has made this situation more serious (Hammad \& Ali, 2014). Currently, it is documented that drought have significantly reduced the yield of soybean (33.1-12.2\%), maize (11.6\%) and wheat (9.2\%) (Matiu et al., 2017).

Plant encounters drought stress when water lost exceeds the water uptake or when the water supply to the roots is disturbed. Plants have developed a wide range of mechanisms to adapt and maintain survival and productivity under water stress. These responses comprise complex mechanisms, inducing various morphological, biochemical, physiological, and molecular aspects resulting in either drought avoidance, escape or drought tolerance, and the mechanism is highly varied among plant species (Lee et al., 2005).

Growth of plants that reflects water stress can be measured through many different parameters, such as fresh weight, stem diameter and leaf area. A previous study by Chartzoulakis et al. (2002) demonstrated that the total plant leaf area and its dry weight were reduced by more 
than $50 \%$ when the plants experienced moderate water stress. Changes in the leaf morphological and anatomical characteristics induced by water deficit can also be observed in avocado plants. Water stress can also influence the chlorophyll content of the plants, as reported in Glycine max (Masoumi et al., 2011) and Triticum aestivum (Moaveni, 2011).

Chilli pepper (Capsicum frutescens) from the family Solanaceae is one of the important commercial crops in Malaysia, with a total production of 35,695 $\mathrm{mt}$ in 2018 (DOA, 2018). Approximately 20 wild chilli species have been documented (Nadeem et al., 2011) to be highly in demand and consumed by the worldwide community in terms of daily cooking, either for fresh consumption or processed into pickles, spice or sauce. It has valuable source of antioxidants, as well as vitamins, especially vitamins $\mathrm{A}, \mathrm{B}$ and $\mathrm{C}$. They even contain potassium, iron, magnesium and folic acid, which are good for health, and are low in calories, sodium, protein and carbohydrate (Sahitya et al., 2018). The pungency of chilli is caused by capsicinoids, including major amounts of capsaicin and dehydrocapsaicin. On top of that, it's also equipped with wide arrays of compounds exhibiting anti-inflammatory, anti- allergic, anti-carcinogenic and antioxidative properties (Lee et al., 2005).

The aim of this study is to determine the effect of water deficit on the growth and chlorophyll content of $C$. frutescens. Base on previous studies, it is hypothesised that both the growth and chlorophyll content of $C$. frutescens will decrease as the water treatments decrease. Therefore, this study will help scientists and farmers increase crop productivity under adverse conditions by providing new information on the effect of water deficit on $C$. frutescens. A better understanding of plant adaptation to water stress may help enhance irrigation management practices.

\section{Materials and Methods}

\section{Experimental Design and Field Layout}

Experimental design and field layout were set up based on the method by Owusu-Sekyere et al. (2010). The Randomised Complete Block Design (RCBD) was used, with six treatments, labelled T1 to T6. One hundred fifty (150) polybags were filled with sandy loam soil (500 g). A total of 30 boxes $(0.45 \mathrm{~m} \times 0.45 \mathrm{~m})$ were used. Each box contains 5 polybags. Figure 1 shows the experimental design and field

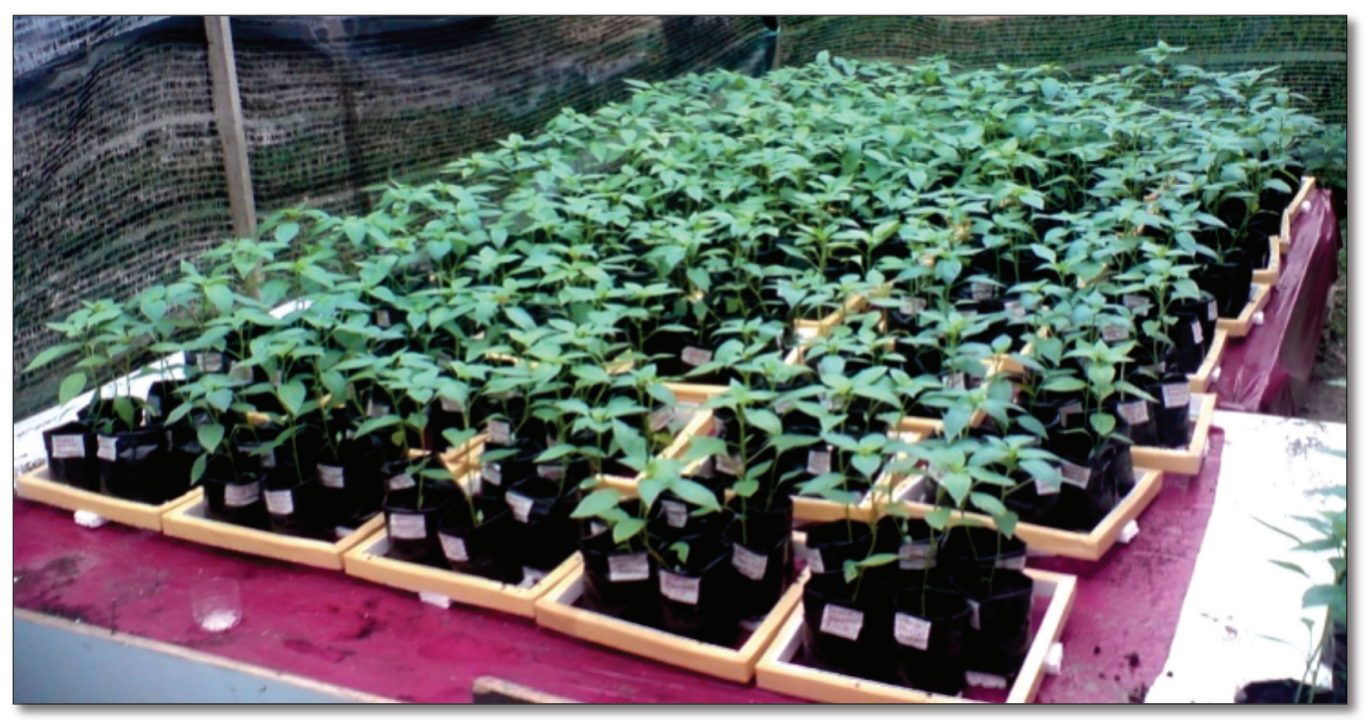

Figure 1: The experimental design and field layout of the C. frutescens study 
layout of the $C$. frutescens using RCBD in a greenhouse. Five replicates from each treatment were chosen using a random table to assay the chlorophyll content and growth measurements.

\section{Plant Materials}

Seeds of $C$. frutescens were obtained from Pertubuhan Peladang Kuala Terengganu, Terengganu, Malaysia. A total of 200 seeds of $C$. frutescens were germinated under the greenhouse. Each polybag $(17 \mathrm{~cm} \mathrm{x} 13 \mathrm{~cm}$ $\mathrm{x} 12.5 \mathrm{~cm}$ ) contained a single seed and was watered with a constant volume of $100 \mathrm{~mL}$ each morning, every day for a month.

\section{Plant Treatments}

A total of 150 two-month-old plants with fully expanded young leaves were treated with 6 different volumes of water: 100, 80, 60, 40, 20 and $0 \mathrm{~mL}$. An amount of $100 \mathrm{~mL}$ water was used for the control group. Five replicates of the plants were randomly selected for 5 different assessment times for each water treatment. The chlorophyll content and growth parameters were measured at $0,5,10,15$, and 20 days of the experiment period.

\section{Determination of Chlorophyll Content}

The chlorophyll content was determined based on the method by Harbone (1984). Under dim light and over ice, $0.15 \mathrm{~g}$ of $C$. frutescens leaf was grounded in a mortar and pestle with 3.0 $\mathrm{mL}$ of $80 \% \mathrm{v} / \mathrm{v}$ acetone. The homogenate was centrifuged at 10,000 rpm for 10 minutes. Then, the absorbance of the supernatant was measured at $663 \mathrm{~nm}$ and $645 \mathrm{~nm}$ using a spectrophotometer (Shimadzu UV-1601). The total chlorophyll content was calculated using the following formula:

$$
\text { Total chlorophyll }=\frac{20.4 \mathrm{~A}_{645}+8.67 \mathrm{~A}_{633} \times \mathrm{V}}{\alpha \times 1000 \mathrm{~mL} \mathrm{x} \mathrm{w}}
$$

where: $\mathrm{w}=$ leaves weight $(\mathrm{g}) ; \mathrm{v}=$ acetone volume $(\mathrm{mL})$ and $\alpha=1.0$

\section{Growth measurements}

Growth was represented by plant height, stem diameter, number of leaves, and leaf area, as well as fresh and dry weight measurements. The growth of $C$. frutescens were determined at 0,5 , 10,15 , and 20 days of treatment.

\section{Plant Height and Stem Diameter}

The plant height was measured from the soil surface to the top of the plant using a measuring tape. The point of measurement for the stem diameter was at the middle part from the base of the main stem. The stem diameter was measured using an electronic digital caliper.

\section{Number of Leaves}

The number of leaves was determined by counting the number of total leaves on each of the plants for each treatment.

\section{Leaf Area}

The leaf area was measured using five randomly selected leaves from each plant. The length, or the longest part along the petiole line of the leaf (Figure 2a), and the width (widest breath across the leaf) (Figure 2b) were measured using a 30 cm ruler (Owusu-Sekyere et al., 1990). The leaf area was calculated using the following formula:

$$
\text { Leaf Area }(\mathrm{LA})=\alpha \times \mathrm{L} \times \mathrm{W}
$$

Where: $\mathrm{L}=$ leaf length $(\mathrm{cm}) ; \mathrm{W}=$ leaves and $\alpha=$ 0.75 (factor used for determination of leaf area in Capsicum)

\section{Fresh and Dry Weights of Leaves}

Five leaves from each plant were selected from each treatment. The leaves were immediately weighed, and the data was recorded. Then, the samples were dried in the oven at $80^{\circ} \mathrm{C}$ for 2 days or until their final weight was constant to determine their dry weight.

\section{Statistical Analysis}

The data was analysed using the SPSS software (Version 25) and the data was expressed as mean 

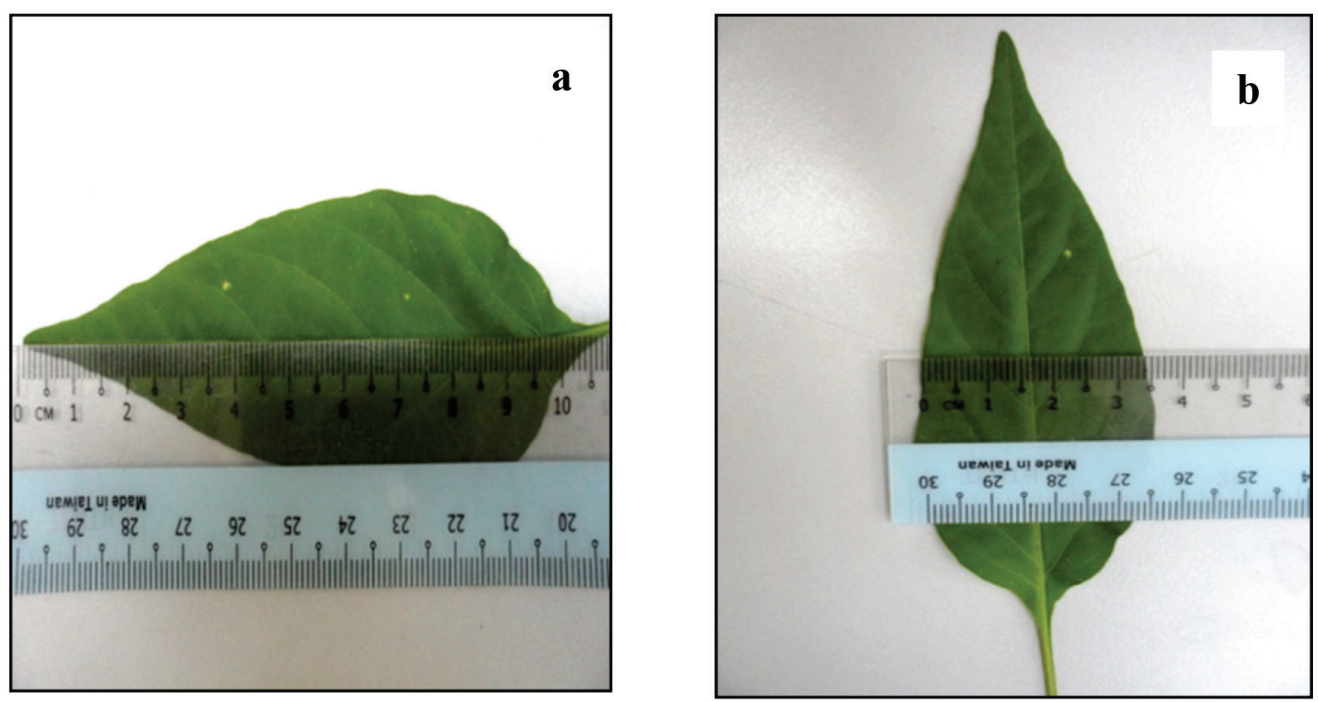

Figure 2: Length (a) and width (b) of the leaf

\pm standard error. Comparison of the growth and chlorophyll content of $C$. frutescens among the different water treatments and days of treatments were tested using two-way ANOVA at $\alpha=0.05$ as the significant level.

\section{Results}

Effect of different volumes of water on the growth of $C$. frutescens

\section{Plant Height}

Figure 3 shows that there was no significant difference $(p>0.05)$ in plant height between treated and control plants at early stages of the treatment period. On day 10 , plants treated with 0 , 20 and $40 \mathrm{~mL}$ of water were significantly higher $(p<0.05)$ in terms of plant height compared with other treated plants. However, after 10 days, the plant height in plants treated with 0 and $20 \mathrm{~mL}$ of water was reduced significantly $(p<0.05)$ and was unaffected at 20 days.

\section{Stem Diameter}

There was no significant difference $(p>0.05)$ observed in all treated and control plants throughout the treatment period (Figure 4). The mean for stem diameter ranged from $4.7 \pm 0.33$ to $6.3 \pm 0.88 \mathrm{~mm}$.

\section{Number of Leaf}

The total number of $C$. frutescens leaves were not significantly affected $(p>0.05)$ in the treated and control plants at the early stages of treatment period. The number of leaves increased significantly $(p<0.05)$ after 10 days, especially in plants treated with $100 \mathrm{~mL}$ of water with values of $16.7 \pm 0.88$. The leaf number doubled up to $32.3 \pm 1.76$ at 20 days of treatment period (Figure 5).

\section{Leaf Area}

A similar pattern was observed in leaf area, where it was unchanged at the early stages of the treatment period. However, after 15 days, the leaf area of the control plants increased significantly $(p<0.05)$ with a maximum value of $158.84 \pm 10.32 \mathrm{~cm}^{2}$, followed by plants treated with $80 \mathrm{~mL}$ of water, with a value of $140.85 \pm 14.01 \mathrm{~cm}^{2}$ (Figure 6).

\section{Fresh and Dry Weights}

No significant difference $(p>0.05)$ was observed in fresh and dry weights of $C$. frutescens in the treated and control plants up to 15 days of treatment. After 15 days, the fresh weight shot up to $2.56 \pm 0.08 \mathrm{~g}$ in the control plants and $2.30 \pm 0.12 \mathrm{~g}$ in the plants treated with $80 \mathrm{~mL}$ of water (Figure 7). Meanwhile, dry weight at 


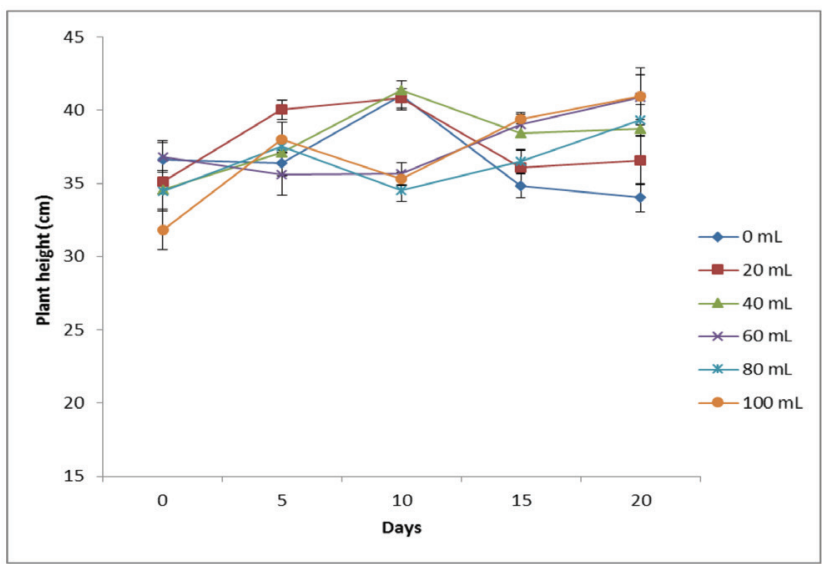

Figure 3: Changes in plant height of C. frutescens treated with different volumes of water. Data are presented as mean \pm standard error $(n=5)$

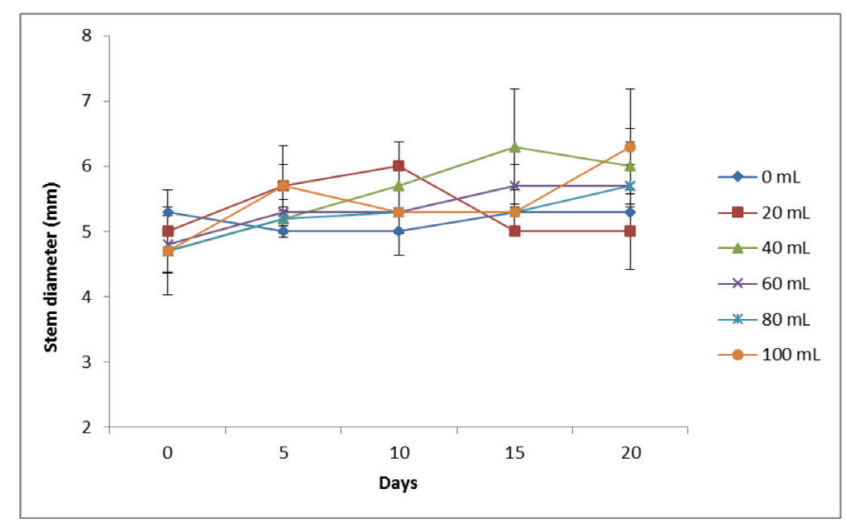

Figure 4: Changes in stem diameter of $C$. frutescens treated with different volumes of water. Data are presented as mean \pm standard error $(n=5)$

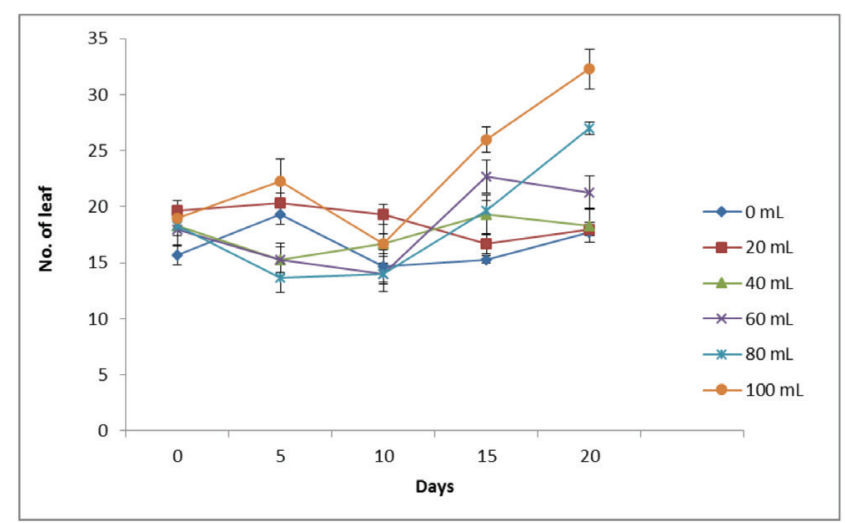

Figure 5: Changes in number of leaves of $C$. frutescens treated with different volumes of water. Data are presented as mean \pm standard error $(\mathrm{n}=5)$ 


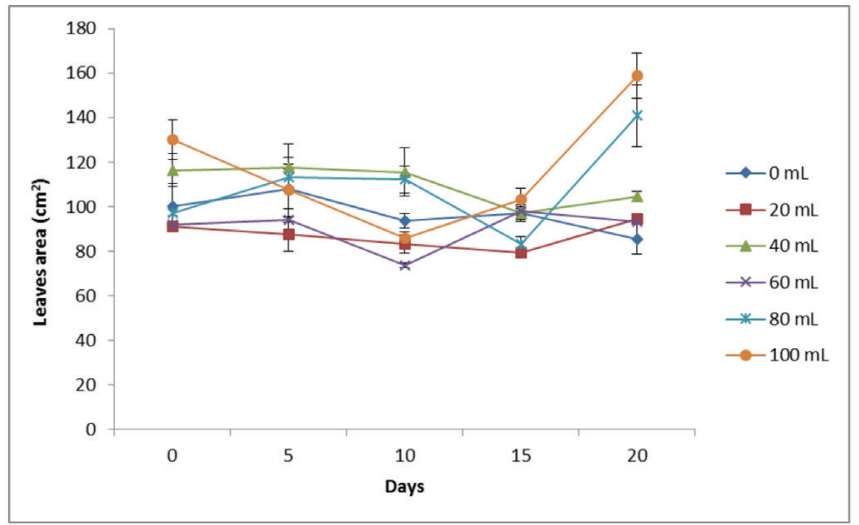

Figure 6: Changes in leaf area $\left(\mathrm{cm}^{2}\right)$ of $C$. frutescens treated with different volumes of water. Data are presented as mean \pm standard error $(\mathrm{n}=5)$

later stages of the experiment was the highest in plant treated with $80 \mathrm{~mL}$ of water with a value of $0.55 \pm 0.05 \mathrm{~g}$, followed by plants treated with $60 \mathrm{~mL}$ of water with a value of $0.32 \pm 0.06 \mathrm{~g}$. No significant difference $(p>0.05)$ was observed in the other treated plants (Figure 8).

\section{Effect of Different Volumes of Water on the Chlorophyll Content of Capsicum frutescens}

The results show that there was no significant difference $(p>0.05)$ in the chlorophyll contents of the $C$. frutescens in treated and control groups up to 15 days of experiment. At the end of the treatment period, the chlorophyll content increased significantly $(p<0.05)$ in plants treated with 100 and $80 \mathrm{~mL}$ of water. The chlorophyll contents in the other treated plants reduced significantly by almost $80 \%$ at 20 days of treatments (Figure 9).

\section{Discussion}

\section{Effect of Different Volumes of Water on the Growth of $C$. frutescens}

In this study, the growth of $C$. frutescens was assessed by measuring plant height, stem diameter, number of leaves, leaf area, as well as fresh and dry weights. The height and stem diameters of $C$. frutescens did not show much difference throughout the experimental period. However, lower volumes of water inhibit the plant height at later stages of the experiment.

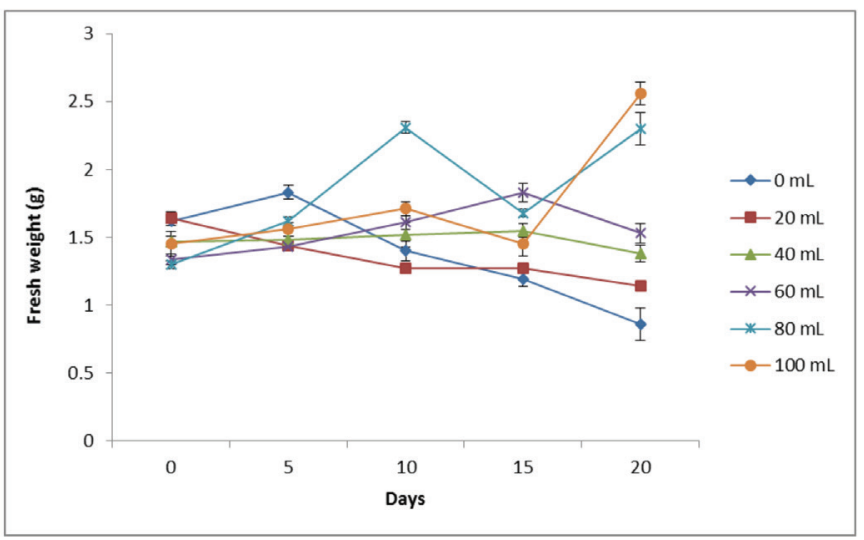

Figure 7: Changes in fresh weight $(\mathrm{g})$ of $C$. frutescens treated with different volumes of water. Data are presented as mean \pm standard error $(n=5)$ 


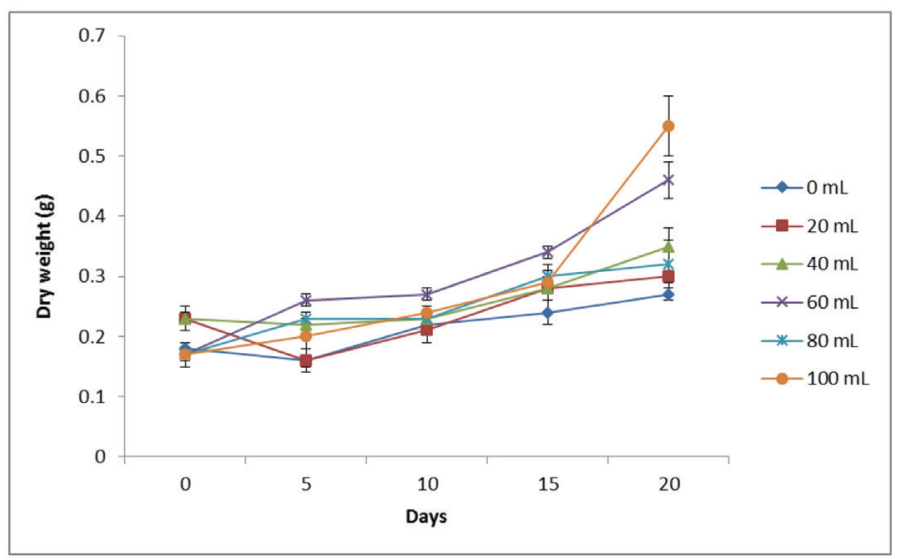

Figure 8: Changes in dry weight (g) of C. frutescens treated with different volumes of water. Data are presented as mean \pm standard error $(\mathrm{n}=5)$

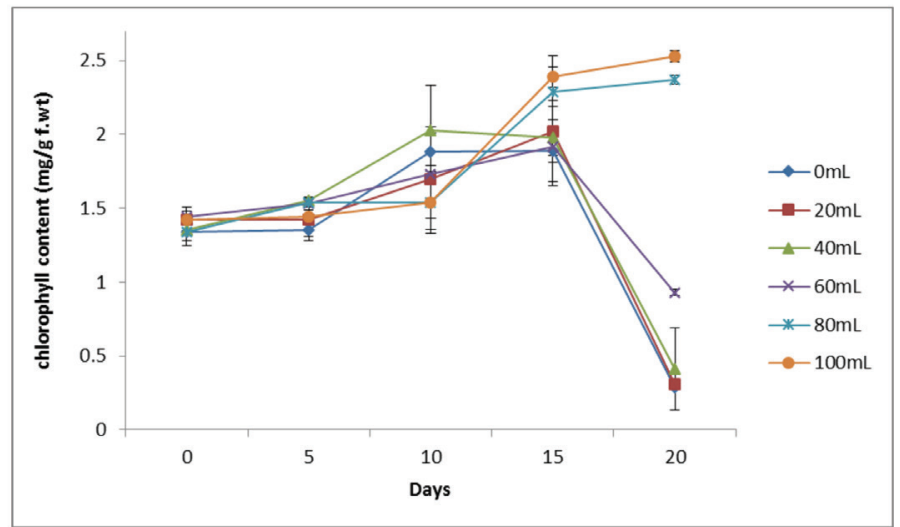

Figure 9: Changes in chlorophyll content ( $\mathrm{mg} / \mathrm{g}$ fwt) of $C$. frutescens treated with different volumes of water. Data are presented as mean \pm standard error $(\mathrm{n}=5)$

As stated by Din et al. (2011), plant growth is controlled by several factors, but water plays a major role, in which a small decrease in water availability to growing plants immediately reduces its metabolic and physiological functions. Variations in plant height among genotypes might also be a sign that different genotypes have different water requirements for their physiological and biological processes (Zubaer et al., 2007). Aliche et al. (2020) postulated that stem growth reduction during water stress may also serve an advantageous purpose for the plants in order to reduce transport distance. This suggests that stem growth reduction under limited water availability can facilitate efficient water, nutrient and assimilate transports in plants.

On the other hand, in this recent study, stem diameter was similar to each other during the period of treatment. As proposed by Brian (1988), the effect of water deficit on plant growth can have both short- and long-term effects. Processes, such as stomata opening or closure, can be observed within minutes, whereas leaf expansion (leaf area) may be affected over a period of months. Stem diameter was also included as long-term effect of water deficit. The growth of the stem diameter was strongly modulated by both cell division and cell expansion (Skirycz \& Inze, 2010). The results 
obtained in this study were in accordance with the results of Perrier et al. (2017) and Fracasso et al. (2016). They found that water deficit did not significantly affect the diameter of Sorghum internodes. The present study is not in line with some other studies of Zheng et al. (2016), who reported that stem diameter in rice plant was reduced proportionally to drought intensity and contributed to the reduction of stem biomass.

The number and total leaf area was not totally diverse in range, but the control plants and plants treated with $80 \mathrm{~mL}$ of water showed an increase in both parameters at the end of the experimental period. Water deficit induced a reduction in leaf area expansion by leaf wilting and rolling. This occurs as a result of cell losing its rigidity due to insufficient soil moisture, less growth and health (Zobayed et al., 2007). Reduced turgor pressure in the leaves is associated with the interruption in water flow from the xylem to other elongating cells. As a result, the decreased rate of both cell division and elongation may possibly cause a smaller leaf area, while slow leaf initiation rate leads to reduced number of leaves. These phenomena were also spotted in other crop plants as a response to chilling and drought stress (Taiz \& Zeiger, 2006; Lukatkin et al., 2012; Jouyban et al., 2013).

Leaves constitute the most important part of the plant body, as it is where photosynthesis takes place. The photosynthates produced are subsequently translocated to all different parts of a plant. Thus, the growth and development, as well as the productivity, of a plant are greatly determined by the active growth of the leaves (Hussain \& Ali, 2015). The leaf growth of $C$. frutescens was related to the water received as the fresh and dry weights of the leaves decreased with the treatment of $0 \mathrm{~mL}$. Water deficit inhibited the uptake of nitrogen, phosphorus and potassium within the plant (Kirnak et al., 2001), which contributed to the changes in the fresh weight of the plant. Compared with other treated plants, leaves in the control plants had increases in both fresh and dry weights. Decreases in leaves fresh and dry weights might be initial evidence of water stress symptoms as observed in Superior Seedless and Razaki grape cultivars (Kamiloğlu et al., 2014). Similarly, Hussain and Ali (2015) proved that the effect of water stress is initially reflected in the leaves, thus affecting the overall growth and development of a plant. Abdalla and El-Khoshiban (2007) also reported that two Triticum aestivum cultivars were found to be affected by water stress due to the reduction in the fresh and dry weights of the shoots. They attributed the decline in fresh weight to the decrease in the water contents of stressed plant cells and tissues, which lose their turgor and thus shrink. In addition, Cakir (2004) also reported that there was a significant dry weight loss in plants under water stress due to stem internodes elongation, delayed ear and ovule development, which reduced the leaf area, grain yield and starch accumulation in endosperm. Water stress did not significantly affect the fresh and dry weights of $C$. frutescens in the earlier treatment period, owing to the irrigation at the beginning of the intensive growth stage, thus exhibiting an increase in plant weight that resulted from a rapid process of biomass accumulation.

\section{Effect of Different Volumes of Water on the Chlorophyll Content of Capsicum frutescens}

Our study also discovered a positive effect between water treatment and chlorophyll content, especially in 40 to $100 \mathrm{~mL}$ treated plants. Chlorophyll content is a good indicator in determining the drought tolerance trait, which specifies photosynthetic efficiency under water stress. Guo et al. (2016) proposed that the decrease in photosynthetic activity is related to the decrease in chlorophyll content of Lycium ruthenicum Murr. seedlings subjected to drought stress. Pirzad et al. (2011) also reported that increasing intensity of drought stress managed to reduce the chlorophyll concentration in seedlings of Matricaria chamomilla. Similar to other plants, severe stress limit the photosynthesis rate of $C$. frutescens. At the same time, starch begins to accumulate, leading to a loss in enzyme activities involved in photosynthesis. Besides, water stress also directly inhibits metabolism 
by limiting the $\mathrm{CO}_{2}$ entry into the leaf, therefore slowing down the carbon fixation rate (Farooq et al., 2009). Hence, a decrease in Rubisco activity, alterations in the photosynthetic pigments, reduced photosynthetic electron transport components that can potentially reduce the molecular oxygen, resulting in the production of ROS, which are deleterious to photosynthetic apparatus (Reddy et al., 2004: Basu et al., 2016).

Water stress is the common ruthless abiotic factor that usually happens in tropical regions, which have high humidity and receive heavy rain throughout the year. Water stress can be induced in two ways, either by water deficit or excess water logging. For example, severe floods may occur during the rainy season, which would generate high concentrations of ROS in plants, which can bring a huge impact on the economic and agricultural sector due to crop production being limited. Thus, plants that live in tropical regions like $C$. frutescens need to develop their own defense mechanism against ROS action (Alsher et al., 2002). Water stress contributes to the excess formation of ROS in treated plants. The imbalanced production of ROS, which is highly reactive and toxic. may lead to oxidative damage, universally known as oxidative stress. The impacts of oxidative stress to plants vary. Oxidative stress usually can decrease plant growth and the chlorophyll content of affected plants.

\section{Conclusions}

The above results indicated that treatment with different volumes of water did not significantly affect the growth of $C$. frutescens. In contrast, the chlorophyll content of $C$. frutescens was notably lowered by water stress, especially at the later stages of the treatment period. The data obtained demonstrated that a deficit in irrigation or water supply is lowered below the maximum levels and mild stress is permitted with nominal effects on the growth of $C$. frutescens. It is suggested that such practice is cost-effective, allowing an optimal use of allocated water, helping farmers to maximise the yields. Further research on the molecular aspects of the response of $C$. frutescens to water stress should be done to increase the understanding of the plant metabolism in water stress as there are other factors affecting the growth and photosynthesis activities of this plant.

\section{Acknowledgements}

The authors wish to thank all parties involved in this project, especially the technical contributions of the staff of the Biochemistry Laboratory, Faculty of Science and Marine Environment, Universiti Malaysia Terengganu.

\section{References}

Abdalla, M. M., \& El-Khoshiban, N. H. (2007). The influence of water stress on growth, relative water content, photosynthetic pigments, some metabolic and hormonal contents of two Triticium aestivum cultivars. Journal of Applied Sciences Research, 3(12), 2062-2074.

Aliche, E. B., Prusova-Bourke, A., Ruiz-Sanchez, M., Oortwijn, M., Gerkema, E., Van As, H., Visser, R. G. F., \& Van der Linden, G. (2020). Morphological and physiological responses of the potato stem transport tissues to dehydration stress. Planta, 251, 45-59. https://doi.org/10.1007/ s00425-019-03336-7.

Alshcer, R. G., Erturk, N., \& Health, L. S. (2002). Role of superoxide dismutases (SODs) in controlling oxidative stress in plants. Journal of Experimental Botany, 53(272), 1331-1341.

Basu, S., Ramegowda, V., Kumar, A., \& Pereira, A. (2016). Plant adaptation to drought stress. F1000 Research. 5:1554. DOI:10.12688/f1000research. 7678.1

Brian, J. M. (1988). Water stress integral- a link between short-term stress and long-term growth. Tree Physiology, 4, 315-323.

Cakir, R. (2004). Effect of water stress at different development stages on vegetative 
and reproduction growth of corn. Field Crops Research, 89, 1-16.

Chartzoulakis, K., Patakas, A., Kofidis, G., Bosabalidis, A., \& Nastou, A. (2002). Water stress affects leaf anatomy, gas exchange, water relations and growth of two avocado cultivars. Science Horticulture, 95, 39-50.

Dietz, K. J., Turkan, I., \& Krieger-Liszkay, A. (2016). Redox- and reactive oxygen species-dependent signaling into and out of the photosynthesizing chloroplast. Plant Physiology, 171, 1541-1550. DOI: 10.1104/ pp. 16.00375

Din, J., Khan, S. U., Ali, I., \& Gurmani, A. R. (2011). Physiological and agronomic responses of canola varieties to drought stress. Journal of Animal and Plant Sciences, 21(1),78-82.

DOA. (2018). Statistik tanaman (Sub-sektor tanaman makanan). Unit Perangkaan, Bahagian Perancangan, teknologi Maklumat dan Komunikasi, Jabatan Pertanian Semenanjung Malaysia.

Farooq, M., Wahid, A., Kobayashi, N., Fujita, D., \& Basra, S.M.A. (2009). Plant drought stress: Effects, mechanisms and management. Agronomy for Sustainable Development, 29(1), 185-212.

Fracasso, A., Trindade, L., \& Amaducci, S. (2016). Drought tolerance strategies highlighted by two Sorghum bicolor races in a dry-down experiment. Journal of Plant Physiology, 190, 1-14.

Guo, Y. Y., Yu, H. Y., Kong, D. S., Yan, F., \& Zhang, Y. J. (2016). Effects of drought stress on growth and chlorophyll fluorescence of Lycium ruthenicum Murr. Seedlings. Photosynthetica, 54(4), 524 -531.

Hammad, S. A. R., \& Ali, O. A. M. (2014). Physiological and biochemical studies on drought tolerance of wheat plants by application of amino acids and yeast extract. Annals of Agricultural Sciences, 59(1), 133-145.
Harbone, J. H. (1984). Phytochemical methods (2nd ed.). London, New York: Chapman and Hall.

Hussain, B., \& Ali, B. (2015). Leaf longevity in plants under water stress-a review. Indian Journal of Plant Sciences, 4(4), 127-133.

Jouyban, Z., Hasanzade, R., \& Sharafi, S. (2013). Chilling stress in plants. International Journal of Agriculture, 5, 2961.

Kamiloğlu, O., Sivritepe, N., Önder, S., \& Dağhan, H. (2014). Effects of water stress on plant growth and physiological characteristics of some grape varieties. Fresenius Environmental Bulletin, 23(9), 2155-2163.

Kirnak, H., Kaya, C., Ismail, T.A.S., \& Higgs D. (2001). The influence of water deficit on vegetative growth, physiology, fruit yield and quality in egg plants. Plant Physiology, 273(3-4), 34-36.

Lee, J. J., Crosby, K. M., Pike, L. M., Yoo, K. S., \& Leskovar, D. I. (2005). Impact of genetic and environmental variation on development of flavonoids and carotenoids in pepper (Capsicum spp.). Science Horticulture, 106(3), 341 -352.

Lukatkin, A. S., Brazaityte, A., Bobinas, C., \& Duchovskis, P. (2012). Chilling injury in chilling-sensitive plants: A review. Agriculture. 99, 111 -124.

Masoumi, H., Darvish, F., Daneshian, J., Normohamadi G., \& Habibi, D. (2011). Effects of water deficit stress on seed yield and antioxidants content in soybean (Glycine max L.) cultivars. African Journal of Agricultural Research, 6(5), 1209-1218.

Matiu, M., Ankerst, D. P., \& Menzel, A. (2017). Interactions between temperature and drought in global and regional crop yield variability during 1961-2014. PLoS ONE, 12(5), $1-23$.

Moaveni, P. (2011). Effect of water deficit stress bon some physiological traits of wheat 
(Triticum aestivum). Journal of Agricultural Sciences, 1(1), 64-68.

Nadeem, M., Anjum, F. M., Khan, M. R., Saeed, M., \& Riaz, A. (2011). Antioxidant potential of bell pepper (Capsicum annum L.)-A review. Pakistan Journal of Food Sciences, 21(1-4), 45-51.

Nita, M., \& Grzybowski, A. (2016). The role of the reactive oxygen species and oxidative stress in the pathomechanism of the age-related ocular diseases and other pathologies of the anterior and posterior eye segments in adults. Oxidative Medicine and Cellular Longevity. Article ID 3164734. http://dx.doi.org/10.1155/2016/3164734

Owusu-Sekyere, J. D., Asante, P., \& OseiBunsu, P. (2010). Water requirement, deficit irrigation and crop coefficient of hot pepper (Capsicum frutescens) using irrigation interval of four (4) days. ARPN Journal of Agricultural and Biological Science, 5,7278.

Reddy, A. R., Chaitanya K. V., \& Vivekanandan, M. (2004). Drought induced responses of photosynthesis and antioxidant metabolism in higher plants. Journal of Plant Physiology, 161, 1189 -1202 .

Sahitya, U. L., Krishna, M. S. R., Sri Deepthi, I. R., Prasad, G. S., \& Kasim, D. P. (2018). Seed antioxidants interplay with drought stress tolerance indices in chilli (Capsicum annuum L) seedlings. BioMed Research International. https://doi.org/10.1155/2018/1605096.

Skirycz, A., \& Inze, D. (2010). More from less: Plant growth under limited water. Current Opinion in Biotechnology, 21,197 -203.
Taiz, L., \& Zeiger, E. (2006). Plant Physiology (4th ed.). Sunderland, MA: Sinauer Associates Inc.

Perrier, L., Rouan, L., Jaffuel, S., ClémentVidal, A., Roques, S., Soutiras, A., Baptiste, C., Bastianelli, D., Fabre, D., Dubois, C., Pot, D., \& Luquet, D. (2017). Plasticity of sorghum stem biomass accumulation in response to water deficit: a multiscale analysis from internode tissue to plant level. Frontier in Plant Science, 8, 1-14. https:// doi.org/10.3389/fpls.2017.01516.

Pirzad, A., Shakiba, M. R., Zehtab-Salmasi, S., Mohammadi, S. A., Darvishzadeh, R., \& Samadi, A. (2011). Effect of water stress on leaf relative water content, chlorophyll, proline and soluble carbohydrates in Matricaria chamomilla L. Journal of Medicinal Plants Research, 5(12), 24832488.

Zheng, M., Tao, Y., Hussain, S., Jiang, Q., Peng, S., Huang, J., Chui, K., \& Nie, L. (2016). Seed priming in dry direct-seeded rice: Consequences for emergence, seedling growth and associated metabolic events under drought stress. Plant Growth Regulation, $78,167-178$.

Zobayed, S. M. A., Afreen F., \& Kozai T. (2007). Phytochemical and physiological changes in the leaves of St. John's wort plants under a water stress condition. Environmental and Experimental Botany, 59, 109 -116.

Zubaer, M. A., Chowdhury A. K. M. M. B., Islam M. Z., Ahmed T., \& Hasan M. A. (2007). Effects of water stress on growth and yield attributes of Aman rice genotypes. International Journal of Sustainable Crop Production, 2(6), 25-30. 